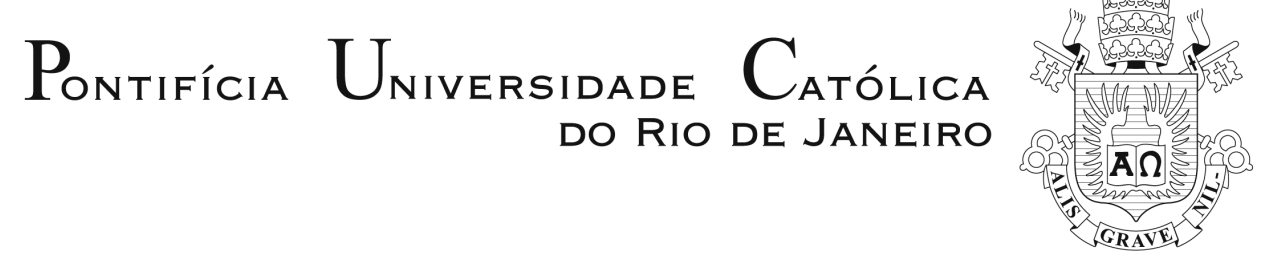

Alexandra de Almeida

\title{
A noção de sublime em Kant e a questão da comoção na arte
}

Dissertação de Mestrado

Dissertação apresentada como requisito parcial para obtenção do grau de Mestre pelo Programa de Pósgraduação em Filosofia do Departamento de Filosofia da PUC-Rio.

Orientadora: Prof. Vera Cristina de Andrade Bueno 


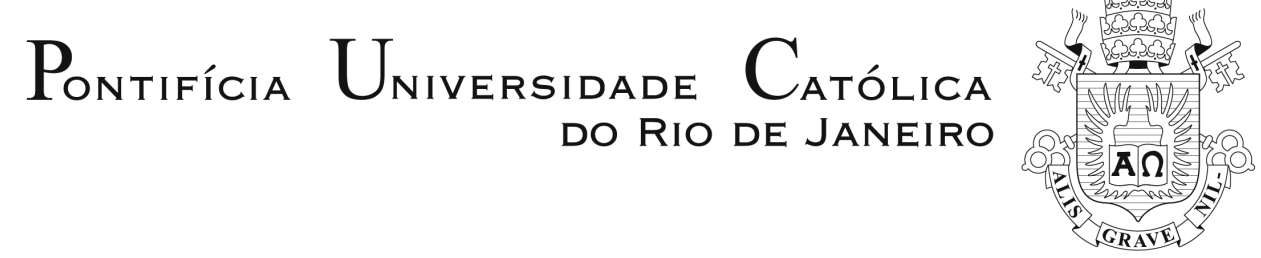

Alexandra de Almeida

\section{A noção de sublime em Kant e a questão da comoção na arte}

Dissertação apresentada como requisito parcial para obtenção do grau de Mestre pelo Programa de Pósgraduação em Filosofia do Departamento de Filosofia do Centro de Teologia e Ciências Humanas da PUCRio. Aprovada pela Comissão Examinadora abaixo assinada.

Prof. Vera Cristina de Andrade Bueno

Orientadora

Departamento de Filosofia - PUC-Rio

Prof. Kátia Rodrigues Muricy

Departamento de Filosofia - PUC-Rio

Prof. Virginia de Araujo Figueiredo

Departamento de Filosofia - UFMG

Prof. Paulo Fernando Carneiro de Andrade

Coordenador Setorial do Centro de Teologia

e Ciências Humanas - PUC-Rio

Rio de Janeiro, 06 de abril de 2009 
Todos os direitos reservados. É proibida a reprodução total ou parcial do trabalho sem autorização da universidade, da autora e do orientador.

\section{Alexandra de Almeida}

Graduou-se em Informática pela Universidade Federal do Rio de Janeiro em 1983. Especializou-se em Computação Gráfica pela PUC-Rio em 1997. Possui mestrado em Design pela PUC-Rio - 2003. É professora do curso de graduação em Desenho Industrial da PUC-Rio. Tem participação em projetos e grupos de pesquisa do Laboratório da Representação Sensível (LaRS), do Dept ${ }^{\circ}$ de Artes \& Design da PUC-Rio.

Ficha Catalográfica

\section{Almeida, Alexandra de}

A noção de sublime em Kant e a questão da comoção na arte / Alexandra de Almeida ; orientadora: Vera Cristina de Andrade Bueno. 2009.

98 f. : il. (color) ; $30 \mathrm{~cm}$

Dissertação (Mestrado em Filosofia)-Pontifícia Universidade Católica do Rio de Janeiro, Rio de Janeiro, 2009.

Inclui bibliografia.

1. Filosofia - Teses. 2. Sublime. 3. Arte. 4. Comoção. 5. Estética. 6. Kant. 7. Lyotard I. Bueno, Vera Cristina de Andrade. II. Pontifícia Universidade Católica do Rio de Janeiro. Departamento de Filosofia. III. Título. 




a Gustavo Amarante Bomfim, em memória, a minha eterna gratidão. 


\section{Agradecimentos}

Não há palavras suficientes para agradecer à Vera. Vera é presente, generosa e muito confiável. A meu ver, qualidades raras em dias turbulentos como os nossos. É apoio constante, calma e clareza em uma só pessoa. Um elogio ter sido orientada por ela.

À família, sempre.

Aos professores do Departamento de Filosofia, cujo pensamento e cujas ações me ajudaram a construir este trabalho.

Aos amigo queridos, todos, do Design, da Filosofia, da vida; todos tão bemvindos e necessários.

À PUC-Rio, pelo auxílio concedido.

Aos funcionários do Departamento de Filosofia. 


\section{Resumo}

Almeida, Alexandra de; Bueno, Vera Cristina de Andrade. A noção de sublime em Kant e a questão da comoção na arte. Rio de Janeiro, 2009. 98p. Dissertação de Mestrado - Departamento de Filosofia, Pontifícia Universidade Católica do Rio de Janeiro.

Em que medida a arte, hoje, nos aproximaria da experiência da comoção como experiência de limites? É a partir desta primeira grande questão que se constrói esta dissertação. Aqui, é proposta uma reflexão filosófica sobre o sublime kantiano como categoria estética, cujo deslocamento, da esfera da natureza para a da arte, nos permitiria cogitar o acesso a um espectador, penso, cada vez mais dominado pela apatia. Trata-se de uma interrogação destinada à produção de arte na atualidade, em especial, às artes visuais, a partir do sublime kantiano.

\section{Palavras-chave}

Sublime, arte, comoção, estética, Kant, Lyotard. 


\section{Abstract}

Almeida, Alexandra de; Bueno, Vera Cristina de Andrade Bueno (Advisor). The sublime in Kant's theory and the issue of emotion in art. Rio de Janeiro, 2009. 98p. MSc. Dissertation - Departamento de Filosofia, Pontifícia Universidade Católica do Rio de Janeiro.

To what extent would art, in our days, bring us closer to the experience of emotion as an experience of limits? It is upon this first important question that this dissertation is built. Proposed herein is a philosophical reflection on Kant's sublime as an aesthetic category whose shift from nature's to art's sphere would allow us to consider the possibility of getting access to a spectator seemingly increasingly dominated by apathy, a characteristic aspect of the mass culture he is inserted into. An interrogation directed towards art's production in present times, in particular in the visual arts, from the perspective of Kant's sublime.

\section{Keywords}

Sublime, art, emotion, aesthetic, Kant, Lyotard. 


\section{Sumário}

1. Introdução 9

2. Na tessitura kantiana: noções e contextos que precedem o sublime 15

3. A noção de sublime em Kant 29

4. A questão da comoção na arte 63

5. Conclusão 86

6. Referências bibliográficas 89

$\begin{array}{ll}\text { Apêndice } & 93\end{array}$ 